\title{
Heterogeneity in the remodeling of aneurysms of the ascending aorta with tricuspid aortic valves
}

E. W. Matthias Kirsch, MD, PhD, ${ }^{a, b}$ N. Costin Radu, MD, ${ }^{a, b}$ Marianne Gervais, PhD, ${ }^{a}$ Eric Allaire, MD, PhD, ${ }^{a, c}$ and Daniel Y. Loisance, MD ${ }^{\mathrm{a}, \mathrm{b}}$

Earn CME credits at http:// cme.ctsnetjournals.org
From the Surgical Research Center, Paris XII University, IFR de Médecine, ${ }^{\text {a }}$ Chirurgie Thoracique et Cardiovasculaire, ${ }^{\mathrm{b}}$ and Vascular Surgery Department, ${ }^{\mathrm{c}}$ Hôpital Henri Mondor, Créteil, France.

Received for publication Jan 30, 2006; accepted for publication April 24, 2006.

Address for reprints: Matthias Kirsch, MD, $\mathrm{PhD}$, Department of Cardiothoracic Surgery, Hospital Henri Mondor, 51 Avenue $\mathrm{M}^{\mathrm{al}}$ de Lattre de Tassigny, 94000 Créteil Cedex, France (E-mail: matthias.kirsch@ hmn.aphp.fr).

J Thorac Cardiovasc Surg 2006;132:1010-16 $0022-5223 / \$ 32.00$

Copyright $(\odot) 2006$ by The American Association for Thoracic Surgery

doi:10.1016/j.jtcvs.2006.04.051
Objectives: The study addresses mechanisms driving the formation of ascending aortic aneurysms by comparing the maximal dilatation area with the transition area immediately adjacent to the normal aortic tissue left in place during surgical repair.

Methods: Aortic wall specimens were taken from the maximal dilatation area and transition area in 10 patients undergoing surgery for ascending aortic aneurysms and fixed for histology and immunohistochemistry for vascular smooth muscle cells (alpha-actin), endothelial cells (CD31), and macrophages (CD68). Tissue concentrations of vascular endothelial growth factor, matrix metalloproteinase-2, and matrix metalloproteinase- 9 were determined by enzyme-linked immunosorbent assay. The results are expressed as medians with their 25 th and 75 th centiles.

Results: Vascular smooth muscle cells were significantly more abundant in the maximal dilatation area than in the transition area $\left(20.3[14.8-24.4] / 10^{-2} \mathrm{~mm}^{2}\right.$ vs $8.0[6.4-9.3] / 10^{-2} \mathrm{~mm}^{2}$, respectively, $P=.002$ ). In the maximal dilatation area, vascular smooth muscle cells had lost their typical lamellar organization, whereas it was preserved in the transition area. Microvessels were significantly more abundant in the media of transition area than in the maximal dilatation area (7.5 $[2.9-10.1] / \mathrm{mm}^{2}$ vs $1.75[1.5-2.0] / \mathrm{mm}^{2}$, respectively, $\left.P=.008\right)$ and were associated with an inflammatory cell infiltration that predominated in their immediate vicinity. There were no significant differences in vascular endothelial growth factor, matrix metalloproteinase-2, and matrix metalloproteinase- 9 between both areas.

Conclusions: The transition area appears as a disease progression front characterized by microvessel formation and inflammatory cell infiltration. In contrast, increased vascular smooth muscle cell density in the maximal dilatation area suggests a healing process, although inefficient to prevent aortic dilatation.

$\mathrm{T}$ The mechanisms driving the dilatation of the ascending aorta during aneurysm formation are poorly understood ${ }^{1}$ and primarily extrapolated from those of abdominal aortic aneurysms (AAAs). ${ }^{2}$ However, the ascending aorta differs widely from the abdominal aorta in terms of hemodynamic strain, periaortic tissues, and embryologic origin of vascular smooth muscle cells (VSMCs). Risk factors also differ between ascending aortic aneurysms (AsAAs) ${ }^{1}$ and AAAs. ${ }^{2}$ Likewise, there is a need to evaluate determinants specific to AsAA development. In this line, a recent report from Tang and colleagues ${ }^{3}$ documented that VSMC density is not decreased in AsAAs, in sharp contrast with AAAs. ${ }^{4}$

Because elective surgery is performed on large AsAAs, the only lesions available for pathologic examination are already developed aneurysms, in which the mechanisms driving disease formation may be exhausted. Thus, differences between normal aortas and AsAAs may reflect adaptation of the enlarged aorta to its new geometry, rather than factors influential in aortic enlargement. Moreover, no animal 


\author{
Abbreviations and Acronyms \\ AAA = abdominal aortic aneurysm \\ AsAA = ascending aortic aneurysm \\ MDA $=$ maximal dilatation area \\ MMP = matrix metalloproteinase \\ $\mathrm{TA}=$ transition area \\ VEGF = vascular endothelial growth factor \\ VSMC $=$ vascular smooth muscle cell
}

model reproduces enlargement at the level of the ascending thoracic aorta. To obviate these limitations to the understanding of AsAA formation, we compared the maximal dilatation area (MDA) of AsAAs with the transition area (TA), for example, the area of moderately dilated aorta, immediately adjacent to the normal aortic tissue left in place during surgical repair. We reasoned that the TA undergoes early events that drive aneurysmal progression of the ascending aorta, as proposed by Curci and colleagues for AAAs. ${ }^{5}$ We restricted the study to degenerative AsAAs in which changes in the aortic wall are those driving enlargement.

We explored further the contribution of atrophy, VSMCs, endothelial cells, and macrophages in the ascending aortic wall during AsAA progression, all factors modulating AAA formation $^{4,6}$ or expansion. ${ }^{7,8}$ We documented sharp differences between the MDA and TA, suggesting that changes in VSMCs and microvessels are mechanisms likely to influence AsAA formation and progression in patients with tricuspid aortic valves.

\section{Patients and Methods \\ Sample Collection}

Full-thickness aortic wall specimens were obtained from 10 consecutive patients undergoing elective surgery for proximal non-atherosclerotic AsAA associated with a tricuspid aortic valve at Henri Mondor Hospital between December 1, 2001, and May 1, 2002, in accordance with the local ethic guidelines. No patients with bicuspid aortic valves, aortic dissection, or authenticated hereditary connective tissue disorder were included. All distal anastomoses were performed under aortic crossclamping as close to the innominate artery as possible. Aortic tissues were harvested at the MDA and at the junction with the distal anastomosis (TA).

\section{Tissue Handling and Preparation}

Aortic specimens were immediately harvested after aortic crossclamping and placed in saline solution at $4^{\circ} \mathrm{C}$. For each area, samples were (1) fixed in $70^{\circ} \mathrm{C}$ ethanol for 24 hours at $4^{\circ} \mathrm{C}$, embedded in paraffin, cut into $5-\mu \mathrm{m}$ sections perpendicular to the axis, and (2) snap-frozen in liquid nitrogen and transported to the laboratory for storage at $-80^{\circ} \mathrm{C}$ until processing.

\section{Histology}

Immunohistochemistry. Paraffin-embedded sections were stained with orcein, Sirius red. Other sections were labeled with anti-smooth muscle cell alpha actin (clone 1A4, code N 1584, DakoCytomation, Carpinteria, Calif), anti-CD31 for endothelial cells (clone JC/70A, code M0823, Dako, Glostrup, Denmark), antiCD68 macrophages (clone PG-M1, code N 1576, DakoCytomation), and anti-fibrinogen (peroxidase-conjugated rabbit anti-human fibrinogen, code P0445, Dako) antibodies. The secondary biotinylated antibody was an anti-mouse antibody included in the detection kit Vectastain Elite ABC (PK-6102, Vector Laboratory, Burlingame, Calif) with Vector VIP as a substrate (Vector Laboratory), counterstained with hematoxylin (Speci, Vichy, France) and mounted in Eukitt. Negative controls were generated by omission of the primary antibody and with a nonrelevant primary antibody.

Quantifications of immunostained cells were done with a grid in the microscope eyepiece on 5 regularly spaced areas in the intima, media, and adventitia. Cell counts were performed by 2 observers (C. R. and E. A.) who were blinded to the origin of the aortic specimen.

The number of microvessels was quantified on the anti-endothelial (anti-CD31)-stained sections. A microvessel was defined as an endothelial layer surrounding a lumen. Macrophages were first quantified on the anti-CD68-stained sections in 5 random chosen fields. However, as macrophages appeared to be gathered preferentially in the vicinity of microvessels, a second count was made in fields centered around a microvessel. There, macrophages were counted in 2 different areas: (1) less than $200 \mu \mathrm{m}$ from the center of the lumen, and (2) more than $200 \mu \mathrm{m}$ from the center of the lumen.

Quantification of Vascular Endothelial Growth Factor and Gelatinases. Protein extracts from MDA and TA aortic tissue were obtained using $0.1 \%$ Triton X-100 lysis buffer (Sigma Aldrich, Chemie, Steinheim, Germany). Total protein from each sample was quantified by BCA-1 assay (Sigma). Quantification of vascular endothelial growth factor (VEGF), total matrix metalloproteinase (MMP)-2, and total MMP-9 protein level was performed with Quantikine Immunoassay kits (all from R\&D Systems Europe, Abingdon, UK).

Statistical Analysis. All continuous variables were expressed as medians with their 25 th and 75 th centiles. Statistical analysis did not assume normal distribution and was performed using nonparametric methods throughout. Differences between the MDA and TA were tested using the Wilcoxon matched-pairs signed-rank sum (W) test.

\section{Results}

\section{Patient Characteristics and Aortic Specimens}

The median patient age was 62.2 (47.54-70.66) years. Nine patients were male. The median body surface area was 1.93 $(1.82-2.0) \mathrm{m}^{2}$. All aneurysms were fusiform. The median maximum aortic diameter was 57 (53.0-59.5) $\mathrm{mm}$ (range, 49-65 mm), as measured preoperatively by computed tomography and/or echocardiography. 
TABLE 1. Morphometric analysis (values are presented as medians with their 25 th and 75 th centiles, $\mathbf{n}=10$ )

\begin{tabular}{lcccc}
\hline & MDA area & TA area & P value* & \% changet \\
\hline Intima & $4.8(2.4-15.6)$ & $4.5(3.2-11.5)$ & .5 & $-9.8(-61.3)-(53.0)$ \\
Media (mm) & $47.4(34.5-54.4)$ & $56.5(45.2-61.5)$ & .004 & $-17.4(-25.3)-(-10.6)$ \\
Adventitia (mm) & $10.1(7.9-11.4)$ & $7.3(4.1-9.9)$ & .8 & $20.2(-45.7)-(56.0)$ \\
Whole thickness (mm) & $76.6(67.4-91.4)$ & $69.4(66.4-84.4)$ & .56 & $-3.2(-18.1)-(9.2)$ \\
\hline
\end{tabular}

$T A$, Transition area; MDA, maximum dilatation area. *Wilcoxon matched-pairs signed-rank sum test. †Percent change calculated as [(MDA value - TA value $) /(T A$ value $)] \times 100$.

\section{Morphometric Analysis}

Median values of intima, media, and adventitia thicknesses in the MDA and TA are presented in Table 1. The media layer of the MDA was significantly thinner than that of the TA.

\section{Vascular Smooth Muscle Cell Density}

The density of alpha actin-positive cells in the media layer was $20.25(14.75-24.38)$ per $10^{-2} \mathrm{~mm}^{2}$ and $8.0(6.38-9.25)$ per $10^{-2} \mathrm{~mm}^{2}$ in the MDA and TA, respectively $(P=.002$, Figure $1, A)$. In the TA, VSMCs were spindle-shaped and oriented parallel to the elastic laminae, as observed in the normal aortic tissue, whereas in the MDA, VSMC orienta-
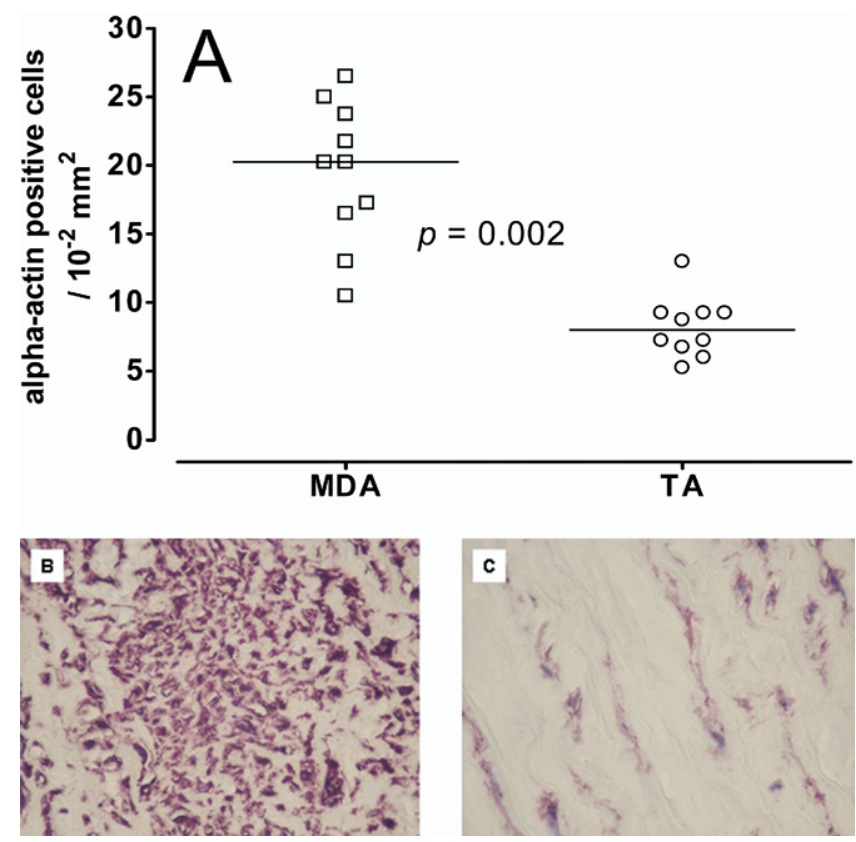

Figure 1. A, Scatterplot of number of alpha-actin positive cells per surface area in the media of aortic specimens taken in the MDA and TA. Horizontal bars represent the median values. B and $\mathrm{C}$, Anti-alpha actin immunostaining counterstained with hematoxylin transverse sections of AsAAs. Note the regular orientation of VSMC nuclei in TA (C), contrasting with their random orientation in MDA (B). Original magnification: $\times 20$. MDA, maximum dilatation area; $T A$, transition area. tion was random, frequently perpendicular to the aortic axis (Figure 1, $B$ and $C$ ).

\section{Microvessels and Macrophage Infiltration}

Microvessels were detected in the media and adventitia in both the MDA and TA. Rare microvessels were observed in the intima in both areas (Figure 2, A). Microvessel lumens were more abundant in the media of TA than in the media of MDA (7.5 [2.88-10.13]/mm ${ }^{2}$ vs $1.75[1.5-2.0] / \mathrm{mm}^{2}$; respectively, $P=.0078$, Figure $2, B)$. Microvessels in the media layer had no preferential orientation. Consecutive cross-sections showed disruption of the elastin network in contact with microvessels in the media, with abundant immunostaining with the antifibrinogen antibody surrounding their lumens (Figure 3).

In contrast with the media layer, microvessel lumens in the adventitia were more abundant in the MDA than in the TA $\left(10.13[7.88-11.38] / \mathrm{mm}^{2}\right.$ vs $7.25[4.13-9.88] / \mathrm{mm}^{2}$, respectively, $P=.039$, Figure $2, C$ ).

VEGF measured by enzyme-linked immunosorbent assay tended to be more abundant in the TA than in the MDA (24.45 [8.34-358.4] pg/mg vs 16.5 [6.0-46.5] $\mathrm{pg} / \mathrm{mg}$ of extracted proteins, respectively, $P=.084$ ).

Macrophage $(\mathrm{CD} 68+)$ infiltration was detected in all aortic layers of both MDA and TA. Overall random macrophage count tended to be higher in the TA than in the MDA (0.9 [0.0-2.9]/0.173 $\mathrm{mm}^{2}$ vs $0.0[0.0-0.4] / 0.173 \mathrm{~mm}^{2}$, respectively, $P=.0625$ ).

In the adventitia in both the TA and MDA, macrophages were preferentially located at some distance from microvessels $(>200 \mu \mathrm{m})$ (Figure 4). In the media of MDA there was no preferential topography of macrophagic infiltration with regard to microvessels, whereas in the media layer of the TA, CD68+ cells were preferentially gathered at the immediate vicinity of microvessel lumen $(\mathrm{CD} 68+$ cells in the TA: $<200 \mu \mathrm{m}$ from vessel lumen: 21.0 [9.0-37.19] per $\mathrm{mm}^{2}$, $>200 \mu \mathrm{m}: 1.88$ [0.88-7.56] per $\mathrm{mm}^{2}, P=.02$, Figure 5).

\section{Matrix Metalloproteinases Expression}

Tissue concentrations of the gelatinases MMP-2 and MMP-9 quantified by enzyme-linked immunosorbent assay were similar in the 2 areas (MMP-2: 25.06 [19.02-68.66] ng/mg 

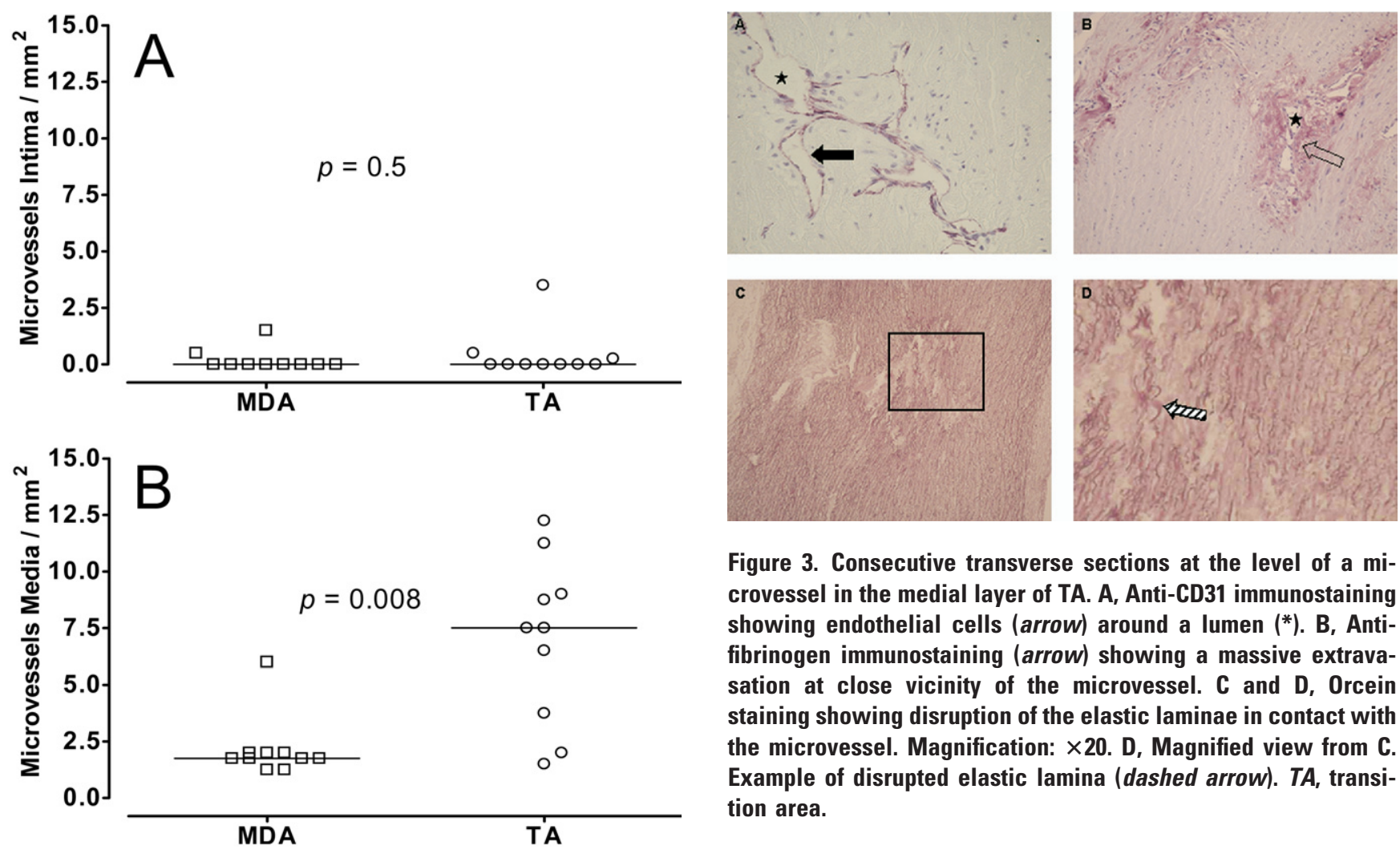

Figure 3. Consecutive transverse sections at the level of a microvessel in the medial layer of TA. A, Anti-CD31 immunostaining showing endothelial cells (arrow) around a lumen (*). B, Antifibrinogen immunostaining (arrow) showing a massive extravasation at close vicinity of the microvessel. C and D, Orcein staining showing disruption of the elastic laminae in contact with the microvessel. Magnification: $\times 20$. D, Magnified view from C. Example of disrupted elastic lamina (dashed arrow). TA, transition area.

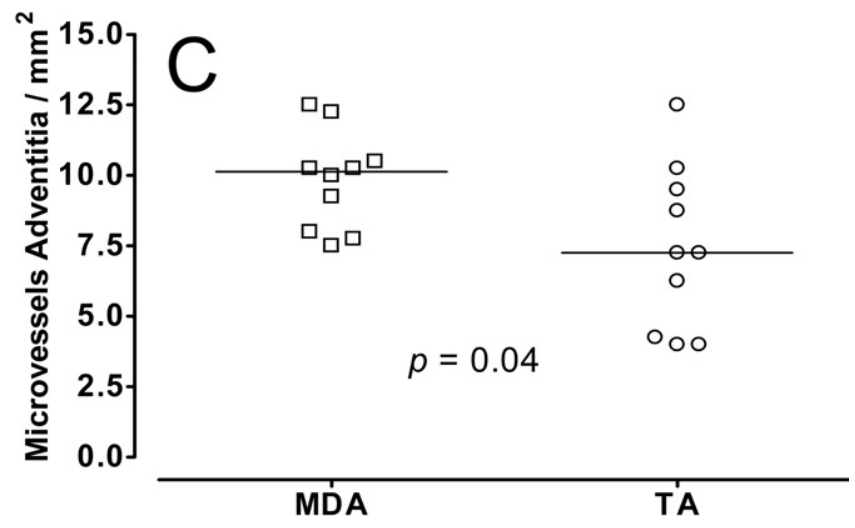

Figure 2. Scatterplot of number of microvessels per surface area in the intima (A), media (B), and adventitia (C) of aortic specimens taken in the MDA and TA. Median values (horizontal bars). MDA, maximum dilatation area; $T A$, transition area.

vs 23.79 [17.16-26.54] ng/mg, $P=.56$; MMP-9: 75.5 [3.5$175.5] \mathrm{ng} / \mathrm{mg}$ vs 14.5 [4.0-92.5] ng/mg, $P=.49$, in the TA and MDA, respectively).

\section{Discussion}

Our study was designed to evaluate cell changes in AsAAs, by comparing MDA and TA, with the assumption that the

non-fully dilated TA represents an area in which early changes that drive aneurysm formation may be observed. We show significant differences between the TA and MDA of AsAAs regarding: (1) the density and orientation of VSMCs, (2) the density of microvessels, and (3) the pattern of macrophage infiltration around microvessels. These differences were observed mostly in the media layer and may provide new insights into the mechanisms driving degenerative aneurysmal enlargement of the ascending thoracic aorta.

Aortic wall thinning is a commonly reported feature of both AsAAs and AAAs, but has rarely been substantiated by
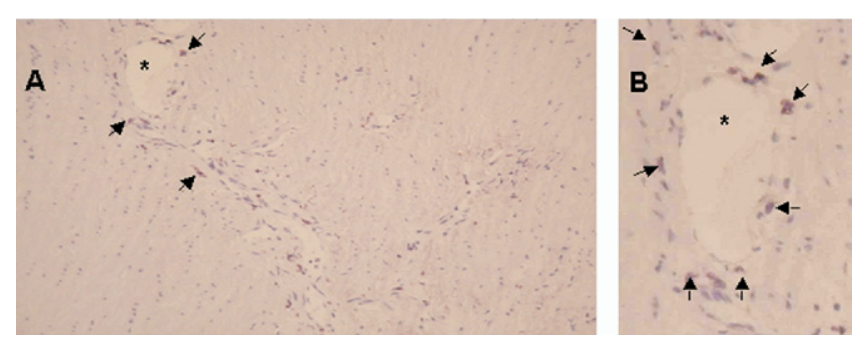

Figure 4. A, Anti-CD68 immunostaining showing the preferential location of macrophages (arrows) around microvessel lumen. Magnification: $\times 20$. B, Magnified view from $A$. 

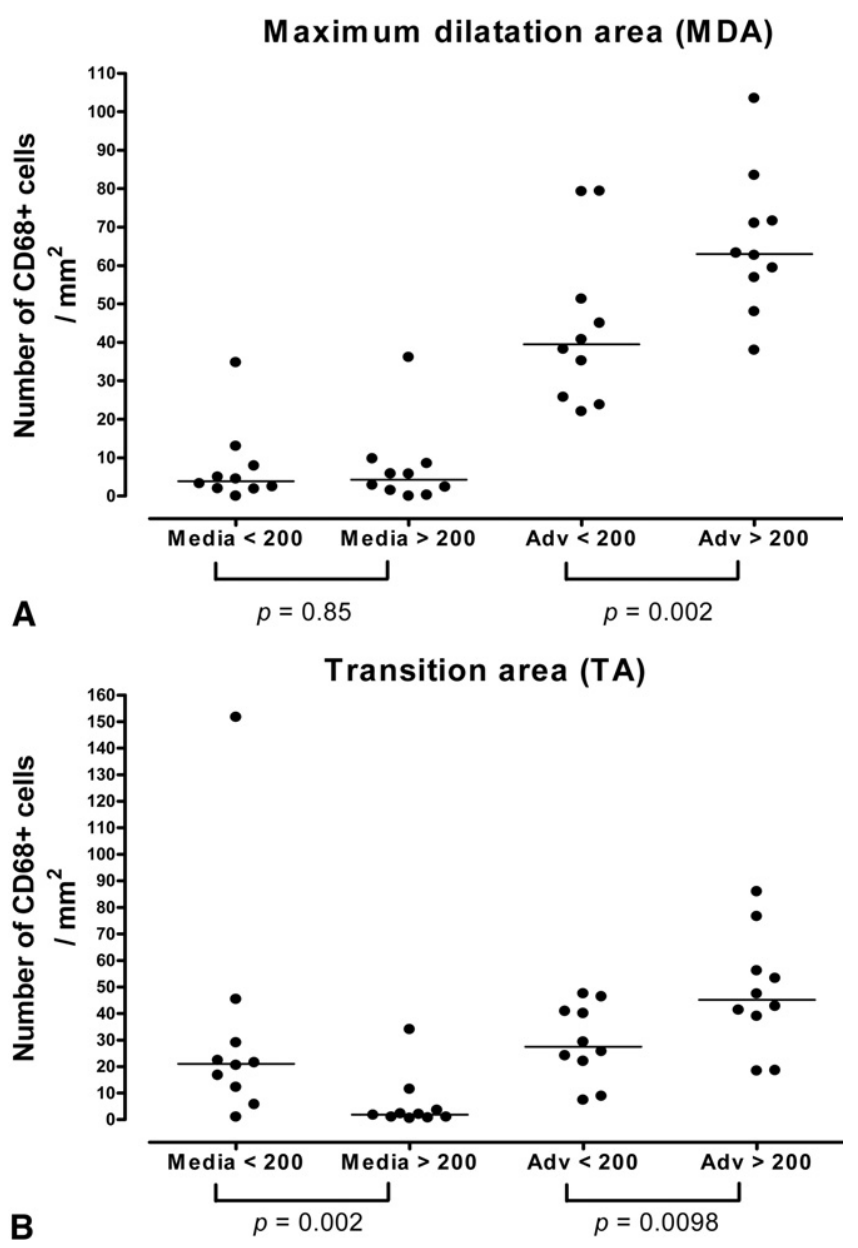

Figure 5. Scattergram of number of CD68 positive cells in media and adventitia of aortic specimens taken from the MDA and TA. Macrophages were counted in 2 different areas around microvessels: $<\mathbf{2 0 0} \mu \mathrm{m}$ and $>\mathbf{2 0 0} \mu \mathrm{m}$ from the center of the lumen. Median values (horizontal bars).

morphometric analysis. ${ }^{9,10}$ In the present study, we observed that the aortic media was significantly thinner in the MDA than in the TA. This medial thinning tended to be compensated by a median increase of $20 \%$ of the adventitial width, resulting in a similar overall aortic wall thickness in both areas. Similar findings were recently reported by Tang and colleagues, ${ }^{3}$ who observed a significant medial thinning in full-thickness aortic biopsies taken from patients with AsAAs compared with nonaneurysmal aortas. However, in contrast with our results, aneurysmal specimens were also characterized by a significantly thickened intima whereas the width of the adventia was similar to that in nondilated aortas.

Medial thinning in aortic aneurysms has been related to VSMC loss. ${ }^{1}$ However, by comparing MDA and TA in patients with tricuspid aortic valves, we observed that the density of $\alpha$-actin positive cells per surface unit is significantly higher in MDA than in the TA. This lies in contrast with the findings of Tang and colleagues, ${ }^{3}$ who reported a similar VSMC density in the body and neck sections of aneurysms. Contradictory results have been reported in the literature regarding VSMC density in the media layer of AsAAs in comparison with nonaneurysmal aortas. Numerous groups have observed up to $25 \%$ medial VSMC loss in aortic wall specimens taken from patients with AsAAs. ${ }^{10-14}$ In contrast, other authors have reported that the number of $\alpha$-actin positive cells per high-powered field was similar in the media of ATAAs compared with that of nonaneurysmal aortas. $^{3,15}$ The findings of Tang and colleagues ${ }^{3}$ even suggest that the total number of aortic VSMCs must have expanded considering the increase of the overall medial area in AsAA. These discrepancies may arise from differences in the cause of AsAAs and technique of VSMC identification. Our data are the first based on a homogenous series of degenerative aneurysms, comparing TA with MDA.

We noted changes in the orientation of VSMCs in the media of AsAAs. Similar observations have been made by other groups, ${ }^{3,16}$ and Bechtel and colleagues ${ }^{16}$ reported that these modifications are both more frequent and more severe in patients with tricuspid valves than in patients with bicuspid valve-related AsAAs. Disordered VSMC orientation appeared to be limited to the MDA, whereas a normal orientation was maintained in the TA. Our observation suggests that TA and MDA reflect 2 different, and probably subsequent, stages of VSMC changes during AsAA formation. Whether these 2 stages of the disease are accompanied by a modulation of VSMC phenotype modulation remains to be determined.

Together with VSMCs, endothelial cells are major cellular components of the vessel wall. In normal aorta, endothelial cells cover the luminal surface of the wall and of the vasa-vasori originating from the adventitia, which supply VSMCs in the media layer with nutriments and oxygen. In the present study, we documented for the first time the presence and modulation of microvessels in the media and adventitia of AsAAs. Microvessel density was significantly higher in the media of TA than in MDA. Because the media in TA is thicker than in MDA, it may be proposed that increased neovessel density may reflect an increase in metabolic needs from a larger tissue mass. However, VSMC density in the media of TA is 2-fold less than in that of MDA, whereas the excess in microvessels is 3 -fold. Therefore, excess in microvessels in TA is unlikely to reflect increased metabolic needs, but may be related to a destructive process operating in TA, as suggested by 2 observations in our study. First, the extracellular matrix around microvesssels appeared to be severely injured, with destruction and disorganization of the elastic laminae. Proteolytic enzymes of the plasmin pathway activating MMPs 
accumulate at the surface of migrating endothelial cells, providing an elastinolytic and collagenolytic environment around sprouting microvessels. ${ }^{17}$ Microvessel leakage shown in our study as a massive extravasation of fibrinogen is another marker of injury elicited by microvessel growth into the media of TA. Second, we observed that macrophages $(\mathrm{CD} 68+)$ are not randomly spread in the media of TA, as they are in the media of MDA and in the adventitia of both areas, but are gathered at the vicinity of the abundant angiogenic microvessels. Microvessel formation and chronic inflammation are associated in 2 ways. ${ }^{18}$ Activated macrophages produce high levels of profactors, including VEGF, ${ }^{19}$ which tends to be in higher amounts in the TA than in the MDA in our study. On the other hand, activated endothelial cells express adhesion molecules by which inflammatory cells are recruited in inflammatory tissues. ${ }^{20,21}$

The association of microvessel, VEGF, and inflammation we observed only in the TA has also been documented in AAA. Infiltration by macrophages and lymphocytes in AAAs is thought to initiate aortic wall destruction through the release of cytokines and proteinases in AAAs. ${ }^{21}$ Contradictory information is reported in the literature regarding inflammation in AsAAs, from clear evidence of macrophage, T-lymphocyte, B-lymphocyte, and natural killer infiltration, ${ }^{13,14}$ to absence of inflammation in the media, with sparse inflammatory cells in the adventitia in some lesions. ${ }^{15}$ Discrepancy between these studies might be related to the heterogenicity of patient groups. Indeed, LeMaire and colleagues ${ }^{22}$ noted no significant inflammatory infiltrate in aortic wall specimens taken from patients with bicuspid valve, but not with tricuspid valve-associated AsATA. Furthermore, most studies were performed on specimens taken at the site of maximal dilatation of the aneurysm. In the present study, we observed macrophage (CD68+) infiltration in all vessel layers of degenerative AsAAs, and an increased macrophage infiltration in biopsies taken from the distal leading edge of AsAAs compared with specimens taken at the site of maximal dilatation.

One limitation of our study is related to the heterogeneity of the TA. Indeed, the TA probably reflects a wide spectrum of aortic wall abnormalities from normal to moderately diseased. Nevertheless, our observations support the view that microvessel development with accumulation of macrophages in their close vicinity reflects an active destruction process predominating in the media of the TA, leading to extracellular matrix destruction and VSMC loss. This probably leads to vessel wall weakening and subsequent dilatation. Conversely, an increase in microvessel density in the adventitia of MDA may reflect an increase in metabolic needs related to VSMC regeneration, as part of a healing process. However, because the diameter of AsAAs increases, one may hypothesize that this healing process in
MDA is insufficient to compensate for vascular wall tension.

\section{References}

1. Kirsch MEW, Radu NC, Allaire E, Loisance D. Pathobiology of ascending aortic aneurysms. Asian Cardiovasc Thorac Ann. 2006;14: 254-60.

2. Sakalihasan N, Limet R, Defawe O. Abdominal aortic aneurysm. Lancet. 2005;365:1577-89.

3. Tang PCY, Coady MA, Lovoulos C, Dardik A, Aslan M, Eleftriades JA, et al. Hyperplastic cellular remodelling of the media in ascending thoracic aortic aneurysms. Circulation. 2005;112:1098-105.

4. Henderson EL, Geng YJ, Sukhova GK, Whittemore AD, Knox J, Libby P. Death of smooth muscle cells and expression of mediators of apoptosis by $\mathrm{T}$ lymphocytes in human abdominal aortic aneurysms. Circulation. 1999;99:96-104.

5. Curci JA, Liao S, Huffman MD, Shapiro SD, Thompson RW. Expression and localization of macrophage elastase (matrix metalloproteinase-12) in abdominal aortic aneurysms. J Clin Invest. 1998;102:1900-10.

6. Allaire E, Muscatelli-Groux B, Mandet C, Guinault AM, Bruneval P, Desgranges $\mathrm{P}$, et al. Paracrine effect of vascular smooth muscle cells in the prevention of aortic aneurysm formation. J Vasc Surg. 2002;36: 1018-26.

7. Allaire E, Muscatelli-Groux B, Pagès C, Guinault A, Goussard A, Mandet C, et al. Vascular smooth muscle cell endovascular therapy stabilizes already developed aneurysms in a model of aortic injury elicited by inflammation and proteolysis. Ann Surg. 2004;239:417-27.

8. Dai J, Losy F, Guinault A, Pagès C, Anegon I, Desgranges P, et al. Overexpression of transforming growth factor-beta 1 stabilizes alreadyformed aortic aneurysms. A first approach to induction of functional healing by endovascular gene therapy. Circulation. 2005;112:1108-15.

9. Agozzino L, Ferraraccio F, Esposito S, Trocciola A, Parente A, Della Corte A, et al. Medial degeneration does not involve uniformly the whole ascending aorta: morphological, biochemical and clinical correlations. Eur J Cardiothorac Surg. 2002;21:675-82.

10. Ejiri J, Inoue N, Tsukube T, Munezane T, Hino Y, Kobayashi S, et al. Oxidative stress in the pathogenesis of thoracic aortic aneurysm: protective role of statin and angiotensin II type 1 receptor blocker. Cardiovasc Res. 2003;59:988-96.

11. Klima T, Spjut HJ, Coelho A, Gray AG, Wukasch DC, Reul GJ, et al. The morphology of ascending aortic aneurysms. Hum Pathol. 1983; 14:810-7.

12. Savunen T, Aho HJ. Annulo-aortic ectasia. Light and electron microscopic changes in aortic media. Virchows Arch (Pathol Anat). 1985; 407:279-88

13. Schmid FX, Bielenberg K, Schneider A, Haussler A, Keyser A, Birnbaum D. Ascending aortic aneurysm associated with bicuspid and tricuspid aortic valve: involvement and clinical relevance of smooth muscle cell apoptosis and expression of cell death-initiating proteins. Eur J Cardiothorac Surg. 2003;23:537-43.

14. Schmid FX, Bielenberg K, Holmer S, Lehle K, Djavidani B, Prasser C, et al. Structural and biomolecular changes in aorta and pulmonary trunk of patients with aortic aneurysm and valve disease: implications for the Ross procedure. Eur J Cardiothorac Surg. 2004;25:748-53.

15. Lesauskaite V, Tanganelli P, Sassi C, Neri E, Diciolla F, Ivanoviene L, et al. Smooth muscle cells of the media in the dilatative pathology of ascending thoracic aorta: morphology, immunoreactivity for osteopontin, matrix metalloproteinases, and their inhibitors. Hum Pathol. 2001; 32:1003-11.

16. Bechtel JFM, Noack F, Sayk F, Erasmi AW, Bartels C, Sievers HH. Histopathological grading of ascending aortic aneurysm: comparison of patients with bicuspid versus tricuspid aortic valve. J Heart Valve Disease. 2003;12:54-61.

17. Carmeliet P. Mechanisms of angiogenesis and arteriogenesis. Nat Med. 2000;6:389-95.

18. Majno G. Chronic inflammation: links with angiogenesis and wound healing. Am J Pathol. 1998;153:1035-9.

19. Xiong M, Elson G, Legarda D, Leibovich S. Production of vascular 
endothelial growth factor by murine macrophages: regulation by hypoxia, lactate, and the inducible nitric oxide synthase pathway. Am J Pathol. 1998;153:587-98.

20. Duplaa C, Couffinhal T, Labat L, Moreau C, Petit-Jean ME, Doutre MS, et al. Monocyte/macrophage recruitment and expression of endothelial adhesion proteins in human atherosclerotic lesions. Atherosclerosis. 1996;121:253-66.
21. Koch AE, Kunkel SL, Pearce WH, Shah MR, Parikh D, Evanoff HL, et al. Enhanced production of the chemotactic cytokines interleukin- 8 and monocyte chemoattractant protein-1 in human abdominal aortic aneurysms. Am J Pathol. 1993;142:1423-31.

22. LeMaire SQ, Wang X, Wilks JA, Carter SA, Wen S, Won T, et al. Matrix metalloproteinases in ascending aortic aneurysms: bicuspid versus trileaflet aortic valves. J Surg Res. 2005;123:40-8.

\section{IN THE MOVE?}

Don't miss a single issue of the journal! To ensure prompt service when you change your address, please photocopy and complete the form below.

Please send your change of address notification at least six weeks before your move to ensure continued service. We regret we cannot guarantee replacement of issues missed due to late notification.

\section{JOURNAL TITLE:}

Fill in the title of the journal here.

\section{OLD ADDRESS:}

Affix the address label from a recent issue of the journal here.

\section{NEW ADDRESS:}

Clearly print your new address here.

Name

Address

City/State/ZIP
COPY AND MAIL THIS FORM TO:

Elsevier Inc.

Subscription Customer Service

6277 Sea Harbor Dr

Orlando, FL 32887
OR FAX TO:

407-363-9661

OR E-mail:

elspcs@elsevier.com
OR PHONE:

800-654-2452

Outside the U.S., call

407-345-4000 